2012-04-06

\title{
Alterophobic bullying and proconformist aggression in a survey of upper secondary school students in Ireland
}

Minton, Stephen

http://hdl.handle.net/10026.1/15020

\subsection{8/17596591211208292}

Journal of Aggression, Conflict and Peace Research

Emerald

All content in PEARL is protected by copyright law. Author manuscripts are made available in accordance with publisher policies. Please cite only the published version using the details provided on the item record or document. In the absence of an open licence (e.g. Creative Commons), permissions for further reuse of content should be sought from the publisher or author. 


\section{Emerald Insight}

\section{Journal of Aggression, Conflict and Peace Research}

Alterophobic bullying and pro-conformist aggression in a survey of upper secondary school students in Ireland

Stephen James Minton

\section{Article information:}

To cite this document:

Stephen James Minton, (2012),"Alterophobic bullying and pro\#conformist aggression in a survey of upper secondary school students in Ireland", Journal of Aggression, Conflict and Peace Research, Vol. 4 Iss 2 pp. 86 - 95

Permanent link to this document:

http://dx.doi.org/10.1108/17596591211208292

Downloaded on: 16 October 2014, At: 04:20 (PT)

References: this document contains references to 30 other documents.

To copy this document: permissions@emeraldinsight.com

The fulltext of this document has been downloaded 57 times since 2012*

\section{Users who downloaded this article also downloaded:}

John Dumay, Lisa Marini, (2012),"Bullying in context: a risk management perspective", Journal of Human Resource Costing \&amp; Accounting, Vol. 16 Iss 4 pp. 281-301

Ståle Einarsen, (1999),"The nature and causes of bullying at work", International Journal of Manpower, Vol. 20 Iss 1/2 pp. 16-27

Helge Hoel, Dieter Zapf, Cary L Cooper, (2002),"Workplace bullying and stress", Research in Occupational Stress and Well-being, Vol. 2 pp. 293-333

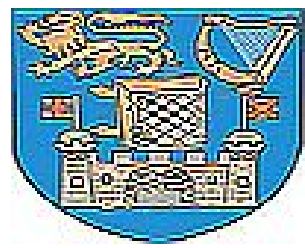

Access to this document was granted through an Emerald subscription provided by 327720 []

\section{For Authors}

If you would like to write for this, or any other Emerald publication, then please use our Emerald for Authors service information about how to choose which publication to write for and submission guidelines are available for all. Please visit www.emeraldinsight.com/ authors for more information.

\section{About Emerald www.emeraldinsight.com}

Emerald is a global publisher linking research and practice to the benefit of society. The company manages a portfolio of more than 290 journals and over 2,350 books and book series volumes, as well as providing an extensive range of online products and additional customer resources and services.

Emerald is both COUNTER 4 and TRANSFER compliant. The organization is a partner of the Committee on Publication Ethics (COPE) and also works with Portico and the LOCKSS initiative for digital archive preservation. 


\section{Invited paper}

\section{Alterophobic bullying and pro-conformist aggression in a survey of upper secondary school students in Ireland}

Stephen James Minton

Stephen James Minton is a Lecturer in Psychology of Education in the School of Education, Trinity College, Dublin, Ireland.

The author would like to acknowledge the generous financial support of the Arts and Social Sciences Benefactions Fund, Trinity College Dublin. $\mathrm{He}$ would also like to thank the students who took part in the survey, and their schools, principals and teachers, for their co-operation.

\begin{abstract}
Purpose - "Alterophobia", which refers to prejudice directed towards members of "alternative" sub-cultures, has been manifest in criminal cases such as the murder of Sophie Lancaster in 2007 (UK). The purpose of this paper is to investigate whether alterophobia is also evident in patterns of school bullying behaviour.

Design/methodology/approach - A total of 820 fifth-year students (16-17 years old; 339 male (41.3 per cent), 481 female (58.7 per cent), at nine secondary schools in Ireland, were asked to respond to a short, specifically constructed questionnaire, concerning membership of groups and sub-cultures, and bullying behaviour.

Findings - Self-identified membership of sub-cultures was infrequent; reports of perceiving that one was identified by others as a member of a sub-culture were more frequent. Self-identified members of sub-cultures reported both having been bullied and having bullied others more frequently than did members of the general sample. Participants expressed that members of "alternative" sub-cultures ("moshers/rockers", "goths", and "emos") were more likely to be bullied, and that members of "non-alternative" sub-cultures ("chavs" and "D4s") were more likely to bully others. It was concluded that "alterophobic bullying" was a reality, and that members of "alternative" sub-cultures may be considered to be "at risk" of being bullied.
\end{abstract}

Research limitations/implications - This study is based on a simple and original questionnaire, and therefore provides indicative/exploratory findings; if a subsequent survey method were attempted, equivalent definitions of sub-cultures would have to be ensured. It is possible to see how alternative research methods (e.g. focus groups) would permit for advances in understanding in this area.

Practical implications - It is suggested that specific mention of alterophobia in school anti-bullying policies should be made, and that closer attention to the psychology of prejudice and "pro-conformist aggression" could inform future anti-bullying efforts.

Originality/value - The paper is the first to focus explicitly on "alterophobia", and provides the first empirical evidence on "alterophobic bullying".

Keywords Alterophobia, Pro-conformist aggression, Bullying behaviour, Secondary schools, Ireland Paper type Research paper

\section{Introduction}

In the early hours of Saturday, 11 August 2007, Sophie Lancaster (20) and her boyfriend, Robert Maltby (21), were attacked by a "mob" of teenagers in Stubbylee Park, Bacup, Lancashire, England (Butt, 2007). Mr Maltby was first attacked, without provocation, and kicked unconscious; the gang then attacked Ms Lancaster, who was trying to protect Mr Maltby (Wainwright, 2008). Both were left comatose, with bleeding on the brain. 
Mr Maltby has since physically recovered, but on 24 August 2007, Ms Lancaster's family agreed to switch off life support after it was confirmed that she would not recover (Butt, 2007). Murder charges were secured against two of the attackers; they were sentenced to life imprisonment. It was widely reported that at the time of the attack that Ms Lancaster and Mr Maltby had been dressed in the "goth" style, and that it was this that had "provoked" the attack (Butt, 2007; Wainwright, 2008).

"Alterophobia" may be defined as "prejudice directed towards members of alternative sub-cultures" (Minton, 2012), including those who are, or are perceived as being, "goths, punks, emos, skaters and fans of heavy metal, and those who listen to any type of alternative music". The prejudice is held to be "based on the way they look and that their musical and other interests differ from the mainstream" (Alterophobia Blogspot, 2011; in Minton, 2012). At present, the term "alterophobia" must be considered to be a neologism; it is seemingly modelled after another form of prejudice that utilises a "-phobia" suffix, homophobia. Prejudicial attitudes have both "external" (behavioural) components and "internal" (affective/cognitive) components (Maio and Haddock, 2009); the "-phobia" suffix refers to the affective component of "irrational fear". For example, homophobia has been defined as "the fear of being labelled homosexual and the irrational fear, dislike or hatred of gay males and lesbians" (Norman et al., 2006, p. 36; italics mine). Certain behavioural components of prejudicial attitudes can and have been legislated against - regarding homophobia, laws prohibiting discrimination and incitement to hatred, in many, but not the majority of countries (Clarke et al., 2010).

Another behavioural manifestation of prejudice is bullying, although bullying itself has been more frequently treated by researchers in the field purely as a sub-category of aggressive behaviour, differentiated on the bases of repetition and the existence of a power imbalance, in the perpetrator's(') favour, existing between the perpetrator(s) and the target(s) (Olweus, 1999; Roland and Idsøe, 2001). A worldwide anti-bullying literature has been built up concerning research (Smith, 2003; Smith et al., 1999) and intervention (Farrington and Ttofi, 2010; Smith et al., 2004). Broad-scale intervention models generally emphasise a "wholeschool emphasis", awareness-raising of bullying as an issue of concern, the provision of training and resources on the basis of implementing behavioural management strategies and policies, and outcome study evaluation (Smith et al., 2004); in terms of outcomes, programmes have typically met with partial success (Farrington and Ttofi, 2010; Smith et al., 2004).

Attempts have been made to identify the psychological characteristics of those involved in bully/victim problems (Olweus, 1999). These have included identifying the existence of higher levels of proactive aggression amongst perpetrators of bullying behaviour (Roland and Idsøe, 2001) and higher levels of reactive aggressive amongst targets of bullying behaviour (Salmivalli and Nieminen, 2002). However, it could be argued that rather less in the way of new theoretical positions has emerged. A notable exception to this is Salmivalli's "participant roles" approach (Salmivalli et al., 1996), which has facilitated an understanding of the interpersonal dynamics of bullying situations, and been related to children's sociometric status (Björkqvist and Österman (1999)). Coincidentally, Morita et al. (1999), in their attempt to find a Japanese-language equivalent for the English word "bullying", report that acts of school violence in Japan are usually thought of along "group process" lines. The Japanese word ljime is defined as "a type of aggressive behaviour by which someone who holds a dominant position in a group-interaction process, by intentional or collective acts, causes mental and/or physical suffering to another inside a group" (p. 311). An interesting point about ljime is not only that it happens in the context of a group - after all, classic social psychology (see Latané (1981) for a review) teaches us that one's propensity to behave antisocially is higher if one is afforded the anonymity of a group - but that that the perpetrators feel that they have the right to join in bringing someone "into line".

Similarly, in researching "sexual bullying", Duncan (1999) provides a concrete example of how patterns of "gender policing" - the aggressive manipulation of friendship and peer groups involved in maintaining the rigid patterns of heteronormativity that exist in some schools - were manifested in the groups of British teenagers involved in his study. 
In an exploratory survey of the experiences of homophobic bullying amongst 123 young lesbian, gay, bisexual and transgendered (LGBT) people in Ireland, over half of the respondents reported having been bullied at school within the last three months; it was concluded that the LGBT population could be considered "at risk" in the school population (Minton et al., 2008). In the biggest empirical study of sexual orientation and bullying to date ( $n=3,046$ tenth-grade students in Norwegian schools), 48.0 per cent of homosexual boys and 17.7 per cent of homosexual girls, compared with 7.3 per cent of heterosexual boys and 5.7 per cent of heterosexual girls, reported having been bullied in the last three months (Roland and Auestad, 2009). In Ireland, male homosexuality was illegal as recently as 1993; however, in 2010, schools were officially instructed to specifically reference homophobic bullying in their anti-bullying policies (O'Higgins-Norman et al., 2010).

Surveys of the incidence of bullying behaviour in a number of countries show a peak in incidence in the mid-teens (Minton, 2010; Smith et al., 2004), seemingly bearing out Erikson's (1963, p. 236) observation that, "young people can also be remarkably clannish and cruel in their exclusion of all those who are different". Although adolescence is often seen as a time of experimentation, certain aspects of adolescent thought seem rather to evidence rigidity and conformity - the neo-Piagetian Labouvie-Vief (1982) pointed out that adolescents tend to be overly literal, or "black and white" in their application of logic to their thinking, whereas the adult world is better served by a thinking style of relativism. Significantly, in their recent study of immigrant and non-immigrant children in Norway, Fandrem et al. (2010) found evidence for bullying behaviour as a means of affiliation immigrant boys in particular were more often identified as bullies, and more often bullied targets together with others.

Identifiable sub-cultures to which those in adolescence and adulthood might belong have been discernible for over 50 years; in the UK context, dating back to and even beyond the "mods" and "rockers" of the early 1960s (Cohen, 2002). Accordingly, a substantial academic literature has been devoted to understanding and explaining the membership, activities and functions of sub-cultures (Hodkinson, 2002). Social identity theory, which examines both how self-concept is influenced by group membership (Turner and Reynolds, 2010) and how social identity reciprocally affects intra- and inter-group behaviour (Turner and Oakes, 1986), has also been applied in understanding inter-group conflict (Tajfel and Turner, 1986). However, whilst the popular media, and even the social scientists, have not shirked in documenting antisocial aspects of the behaviour of some members of "alternative" sub-cultures (Cohen, 2002), precious little outside general news items (Butt, 2007; Wainwright, 2008) exists concerning members of "alternative" sub-cultures as targets of aggression. As we have seen, the phenomenon of homophobic bullying in schools has, in very recent years, developed a literature of its own (Minton et al., 2008; Norman et al., 2006; Clarke et al., 2010; Duncan, 1999), but the bullying of young people at school on the basis of their actual or perceived membership of "alternative" sub-cultures has not, to this author's knowledge, yet received the attention of an empirical study. This article marks an attempt to open that potential field of enquiry.

Hence, the hypotheses that were examined in the present survey of upper secondary school students were that:

- Considering the conformity and absolutism typical of adolescent thought (Erikson, 1963; Labouvie-Vief, 1982), reported membership of sub-cultures amongst upper secondary school students will be low, especially membership of "alternative" sub-cultures.

And, given the likely existence of alterophobia (Butt, 2007; Wainwright, 2008) and as prejudice may be behaviourally manifested in patterns of bullying behaviour (Minton et al., 2008; Norman et al., 2006):

- Reports of having been bullied will be more frequent amongst members of "alternative" sub-cultures than amongst members of "non-alternative" sub-cultures and the general sample.

PAGE 88 | JOURNAL OF AGGRESSION, CONFLICT AND PEACE RESEARCH | VOL. 4 NO. 22012 
- Participants in general will perceive that members of "alternative" sub-cultures were more likely to be bullied than were both members of "non-alternative" sub-cultures, and the general sample.

\section{Method}

\section{Participants}

In May 2010, 820 fifth-year (aged 16-17 years) second-level school students (339 male (41.3 per cent), 481 female (58.7 per cent)) at nine schools completed a short, simple questionnaire concerning membership of groups and sub-cultures, and bullying behaviour. The schools involved covered the entire geographical area of the Republic of Ireland, and included a balance of single and mixed-gender student enrolment; rural/urban location; and, secondary and vocational type schools, in line with national characteristics. The schools' participation was voluntary, and on the basis of the principals' responses to the author's invitation to be involved.

\section{Materials}

The questionnaire which was used was constructed specifically for this study. On it, participants were instructed that, "The following questions are about groups or sub-cultures to which some young people belong. Again, please try to answer them as carefully and as honestly as you can. There are no right or wrong answers - choose the answer(s) which match(es) your opinion", and "Don't put your name on this form. No-one will know how you have answered these questions. But it is important that you answer the questions carefully and honestly". For the purposes of the questionnaire, bullying behaviour was defined as follows (the author's translation of a definition supplied in a questionnaire used previously in a Norwegian study of sexual orientation and bullying (Roland and Auestad, 2009)):

We say it is bullying when a person or people together are repeatedly unfriendly and unpleasant to someone who cannot easily defend himself or herself. This can involve the bullied person being hit, kicked or otherwise physically hurt. It is also bullying when a person is teased or excluded by others.

Participants were asked whether, and how frequently, they had done this to others, or if it had happened to them ("never", "seldom", two or three times per month', "about every week", or "about every day").

Prior to this study, no reliable evidence was available to assist the author in discerning the likely sub-cultures to which teenagers in Ireland might belong. However, a school project on stereotyping undertaken by fourth-year students at one of the participating schools (hence, one school year below the participating students) identified five groups - "chavs", "D4s", "moshers/rockers", "goths" and "emos".

Of these, and according to the definitional aspects of "alterophobia" discussed above (Minton, 2012), "moshers/rockers", "goths" and "emos" (who are all at least partially characterised by their tastes in "alternative" music) may be considered to be members of "alternative" sub-cultures. "chavs" and "D4s" may be considered to be members of "nonalternative" sub-cultures. In the wording of the questionnaire, definitions (based on condensations of those found at Wikipedia) were supplied for these five groups:

1. "A chav is a stereotypical rough young person, typically unemployed or of white working class background, who repeatedly engages in anti-social behaviour, such as street drinking, drug abuse and rowdiness".

2. "D4 describes an Irish liberal elitist attitude, based on the perceived opinions and characteristics of some residents of this area, referring to the alleged wealth and posh life-style of residents. The fictional jock Ross O'Carroll-Kelly[1] was meant as a caricature of this".

3. "Moshers and rockers are typically fans of heavy metal music, and have long hair, wearing jeans, black T-shirts, boots and black leather or denim jackets. T-shirts are generally emblazoned with the logos or other visual representations of favorite bands".

VOL. 4 NO. 22012 |JOURNAL OF AGGRESSION, CONFLICT AND PEACE RESEARCH | PAGE 89 
4. "The goth subculture refers to tastes in music and fashion. Gothic music encompasses a number of different styles, and styles of dress within the subculture range from punk, Victorian, some Renaissance and Medieval style, or combinations of the above, most often with black clothes, make-up and hair".

5. "Emos are stereotyped as wearing skinny jeans, sometimes in bright colors, and tight t-shirts (usually short-sleeved) which often bear the names of emo bands. Emos have been associated with a stereotype that includes being particularly emotional, sensitive, shy, and introverted."

Participants were instructed to answer by marking which of the groups/sub-cultures they felt applied in their responses to the following questionnaire items:

- "I belong to the following group(s)/sub-culture(s)".

- "Other people usually think that I belong to the following group(s)/sub-culture(s)".

- "I think that members of the following group(s)/sub-culture(s) are more likely to be bullied".

- "I think that members of the following group(s)/sub-culture(s) are more likely to bully others". For the last two items, the response options of "None" and "Other (please specify which)" (the latter, of course, in case other sub-cultures should exist) were also available.

\section{Procedure}

Following communication with and having obtained informed consent from the school principals, sufficient copies of the questionnaire and standardised instructions for its administration to all fifth-year students were sent to the nine participating secondary schools. It was noted that it would take no longer than 15-20 minutes for a student to complete the questionnaire; that questionnaires were to be filled in entirely anonymously and confidentially; and, that schools' participation in the survey would be treated as a matter of absolute privacy. Class teacher administrators were instructed to seat the students separately; no time limit was to be set for the completion of the questionnaires. Afterwards, the administrators collected up the questionnaires and posted them back to the author. Following the processing of the results, schools were supplied with a copy of their own group-based results.

\section{Results}

\section{Membership of sub-cultures}

Table I presents findings from the participants regarding their reported membership of groups and sub-cultures by both their self-identification, and their perceptions of being identified as such by others.

From Table I, it can be seen that reporting a self-identified membership of sub-cultures was rather infrequent, with reports of no such membership being the most frequently recorded response (76.4 per cent). It was statistically significantly more likely for the participants to report perceiving that they were identified by others as a member of a sub-culture, rather than self-identifying as members, both overall ( $\chi^{2}=61.59$ ( $\left.\left.1 \mathrm{df}\right), p<0.001 ; \Phi_{\mathrm{c}}=0.274\right)$ and for four of the five originally nominated sub-cultures, although association strengths (by Cramer's phi) were modest. This was the case with chavs $\left(\chi^{2}=15.12(1 \mathrm{df}), p<0.001\right.$; $\left.\Phi_{\mathrm{C}}=0.136\right)$, D4s $\left(\chi^{2}=38.04(1 \mathrm{df}), p<0.001 ; \Phi_{\mathrm{c}}=0.215\right)$, goths $\left(\chi^{2}=17.32(1 \mathrm{df}), p<0\right.$. $\left.001 ; \Phi_{\mathrm{c}}=0.145\right)$ and emos $\left(\chi^{2}=11.79(1 \mathrm{df}), p<0.001 ; \Phi_{\mathrm{C}}=0.12\right)$. Specifications of "others" listed in the table above are confined to those categories that received five or more mentions in each case.

\section{Reports of having been bullied or having bullied others}

Table II presents findings from self-identified members of different sub-cultures regarding their reports of having been bullied or having bullied others. As bullying behaviour was (and is universally) defined as repeated behaviour, the criterion that was set for categorizing 
Table I Reported membership of groups and sub-cultures by self-identification and perceived identification by others

\begin{tabular}{|c|c|c|c|c|c|}
\hline Self-ident & $\begin{array}{l}\text { fied } \\
\text { Count }\end{array}$ & Percentage & $\begin{array}{l}\text { Perceived other-identified } \\
\text { Sub-culture }\end{array}$ & Count & Percentage \\
\hline None & 627 & 76.4 & None & 478 & 58.3 \\
\hline Chav & 48 & 5.9 & Chav & 92 & 11.2 \\
\hline D4 & 39 & 4.8 & D4 & 111 & 13.5 \\
\hline Mosher/Rocker & 56 & 6.8 & Mosher/Rocker & 77 & 9.4 \\
\hline Goth & 7 & 0.9 & Goth & 33 & 4.0 \\
\hline Emo & 30 & 3.7 & Emo & 62 & 7.6 \\
\hline Other (Total) & 77 & 9.3 & Other (Total) & 64 & 7.8 \\
\hline Other - Sporty & 21 & 2.6 & Other - Sporty & 13 & 1.6 \\
\hline Other - Indie & 9 & 1.1 & Other - Hippy & 12 & 1.5 \\
\hline Other - Country/Culchie ${ }^{a}$ & 6 & 0.7 & Other - Culchie & 7 & 0.9 \\
\hline Other - Hippy & 6 & 0.7 & Other - Indie & 6 & 0.7 \\
\hline Other - Nerd/Swot/Geek & 6 & 0.7 & & & \\
\hline
\end{tabular}

Note: 'This term refers to a stereotypically "rural" Irish person, and is usually (but not always) a pejorative

participants as having been involved in bullying behaviour was reporting that the bullying had occurred two to three times per month or more frequently (i.e. those who had reported that the bullying had "never" or "seldom" happened were not so categorized). This system was also used in Roland and Auestad's (2009) study, whose definition of bullying was used in the present study.

Given the definitions employed in this survey (see "materials", above), one common feature of moshers/rockers, goths and emos is that the music they listen to and the appearances they effect was seen as being deliberately chosen from outside of the mainstream (hence, constitutes an "alternative"), whereas chav and D4 appearance and culture was seen as an exaggeration of the working-/under-class and elitist/middle-class mainstream cultures, respectively, (hence, is "non-alternative"). From Table II, it may be seen that with the exception of D4s (0 per cent), it was more common for self-identified members of all sub-cultures, rather than for participants in general, to report having been bullied. This was statistically significant (again, with modest association strengths) in the case of moshers/ rockers $\left(\chi^{2}=8.64\right.$ ( $\left.\left.1 \mathrm{df}\right), p<0.01 ; \Phi_{\mathrm{c}}=0.103\right)$ and emos $\left(\chi^{2}=9.40\right.$ (1df), $p<0.01$; $\left.\Phi_{\mathrm{C}}=0.107\right)$. In terms of the other "alternative" sub-culture represented in the sample, the proportion of self-identified goths was too small to accurately calculate $\chi^{2}$. It may also be seen from Table II that, with the exception of goths, it was more common for self-identified members of sub-cultures, rather than for participants in general, to report having bullied others. This was statistically significant (again, with modest association strengths) in the case of chavs ( $\left.\chi^{2}=13.08(1 \mathrm{df}), p<0.001 ; \Phi_{\mathrm{c}}=0.126\right)$ and emos $\left(\chi^{2}=4.66(1 \mathrm{df}), p<0.05\right.$; $\left.\Phi_{\mathrm{C}}=0.075\right)$.

Table II Reports of having been bullied and having bullied others amongst self-identified members of different sub-cultures

\begin{tabular}{lcclrc}
$\begin{array}{l}\text { Reported that they had been bullied } \\
\text { Category }\end{array}$ & $\begin{array}{l}\text { Reported that they had bullied others } \\
\text { Count }\end{array}$ & Percentage & Category & Percentage \\
\hline Sample total & 49 & 6.0 & Sample total & 38 & 4.6 \\
Chav & 5 & 10.4 & Chav & 8 & 16.7 \\
D4 & 0 & 0 & D4 & 2 & 5.1 \\
Mosher/Rocker & 9 & 16.1 & Mosher/Rocker & 3 & 5.4 \\
Goth & 1 & 14.3 & Goth & 0 & 0 \\
Emo & 6 & 20.0 & Emo & 4 & 13.3
\end{tabular}

VOL. 4 NO. 22012 |JOURNAL OF AGGRESSION, CONFLICT AND PEACE RESEARCH | PAGE 91 


\section{Perceptions of members of sub-culture's likelihoods of being bullied and bullying others}

Table III presents findings from the participants regarding their reports of their perceptions that members of different groups or sub-cultures were more likely to be bullied or to bully others.

From Table III, it can be seen that 8.3 and 16.7 per cent of participants in the sample as a whole reported that chavs and D4s, respectively, were more likely to be bullied; 44.9, 80.7 and 87.3 per cent stated that moshers/rockers, goths and emos, respectively, were more likely to be bullied. If these responses are grouped, reports that members of "alternative" rather than "non-alternative" sub-cultures were more likely to be bullied were statistically significantly more frequent, with good association strength $\left(\chi^{2}=1,349.02\right.$ ( $\left.1 \mathrm{df}\right), p<0.001$; $\Phi_{\mathrm{C}}=0.657$ ). Conversely, 88.4 and 44.6 per cent stated that chavs and D4s, respectively, were more likely to bully others; $12.8,6.4$ and 5.6 per cent stated that moshers/rockers, goths and emos, respectively, were more likely to bully others. Again, if these responses are grouped, reports that members of "non-alternative" rather than "alternative" sub-cultures were more likely to bully others were statistically significantly more frequent, again with good association strength $\left(\chi^{2}=1,544.11(1 \mathrm{df}), p<0.001 ; \Phi_{\mathrm{c}}=0.703\right)$.

\section{Discussion}

The first hypothesis, based largely on what developmental psychologists such as Erikson (1963) and Labouvie-Vief (1982) had to say regarding the high levels of conformity and absolutism in adolescent thought, stated that there should be a low reported membership of sub-cultures (especially "alternative" sub-cultures) amongst participants. This was partially supported by the results (Table I) - self-identified membership of a sub-culture was rather infrequent, but self-reported membership of "alternative" sub-cultures was not noticeably lower than that of "non-alternative" sub-cultures. Participants reported perceiving that they were identified by others as a member of a sub-culture more often than they self-identified as members - this is understandable in three ways. First, one is more likely to perceive oneself in individualistic terms; second, the assignation of group membership is akin to stereotyping (something that we do to others); and third, non-members of sub-cultures (here, the majority) are and are perceived as "non-experts", and more likely to emphasise similarities and confuse distinctions between sub-cultures. However, the comparison which was made here was between self-perceived group membership, and perceptions about what others might be thinking. On reflection, this was somewhat more indirect than was necessary; a comparison between self- and peer-estimations would have been both viable, and potentially more instructive.

It was also hypothesised (given what had been examined regarding alterophobia, bullying and homophobic bullying) that one would expect reports of having been bullied to be more frequent amongst members of "alternative" sub-cultures $\left(H_{2}\right)$ and that participants would perceive that members of "alternative" sub-cultures were more likely to be bullied $(H 3)$. Both were supported by the results (Tables II and III) - it was more common for self-identified members of sub-cultures, rather than for participants in general, to report having been bullied (and this was statistically significant in two of the alternative sub-cultures, moshers/ rockers and emos), and (acknowledging the potential confound caused by the descriptions

Table III Reports of perceptions of members of different groups or sub-cultures being more likely to be bullied or to bully others amongst total sample participants

\begin{tabular}{|c|c|c|c|c|c|}
\hline \multicolumn{3}{|c|}{ Perceived as being more likely to be bullied } & \multicolumn{3}{|c|}{ Perceived as being more likely to bully others } \\
\hline Category & Count & Percentage & Category & Count & Percentage \\
\hline Chav & 68 & 8.3 & Chav & 725 & 88.4 \\
\hline D4 & 137 & 16.7 & D4 & 366 & 44.6 \\
\hline Mosher/Rocker & 368 & 44.9 & Mosher/Rocker & 105 & 12.8 \\
\hline Goth & 662 & 80.7 & Goth & 53 & 6.4 \\
\hline Emo & 716 & 87.3 & Emo & 46 & 5.6 \\
\hline
\end{tabular}

PAGE 92 | JOURNAL OF AGGRESSION, CONFLICT AND PEACE RESEARCH | VOL. 4 NO. 22012 
of categories outlined above), it seems that participants did report that members of "alternative" sub-cultures were more likely to be bullied, and members of "non-alternative" sub-cultures were more likely to bully others. It was also recorded that chavs and emos were statistically significantly more likely to report actually having bullied others. This result regarding emos seems surprising; however, if the "emotional, sensitive" aspect of the stereotype bears some truth, it is possible to speculate that the sample's emos may have over-estimated their influence in negatively affecting others. In conclusion, even though the term may not be broadly used, alterophobic bullying was a reality in both the perceptions and experiences of the participants.

One of the most horrifying aspects of the Sophie Lancaster murder case was that after the attack, the killers boasted that they had "done summat [something] good"; indeed, one of those eventually sentenced for Ms Lancaster's murder laughed and joked with his mother about what he had done during initial police interviews (Wainwright, 2008). It may be tempting to see nothing more in this than the bluff, bravado and individual pathology of a murderer, or even the roots of that pathology in his upbringing. However, models of bullying behaviour both West (Salmivalli et al., 1996) and East (Morita et al., 1999) that focus one on the social dynamism that underlies bullying behaviour may prompt one to think about the "social function", if such an adaptive-sounding term could ever be applicable, of group aggressive and bullying behaviour. From Duncan's (1999) description of "gender policing" heteronormative practices, it would appear that when prejudice underlies group aggressive behaviour, the "social function" of that behaviour is to enforce conformity to the aggressors' sense of what constitutes "normative" behaviour or appearances. Hence, in instances of homophobic and alterophobic bullying and attacks, the cognitive component of the underlying prejudicial attitude (it will be recalled that the literal meaning of the word "prejudice" is "pre-judgement", or "judgement without sufficient evidence"), provides aggressors with a so-called "justification" of their actions, to themselves and like-minded others, on the basis of the characteristics of their targets, who are held responsible by the aggressors for their being attacked. I would like to suggest the term "pro-conformist aggression" to describe this pattern.

The results of this survey can easily be interpreted along the lines of "pro-conformist aggression" - not only did the participants expect that the minorities (Table I) who are members of "alternative" sub-cultures to be more likely to be bullied (Table III), but that this was also, in fact, the case (Table II). More generally, and in terms of preventative practice, if aggressors can convince themselves (no matter how spurious their "reasoning" may be) that their behaviour is "justifiable", then where is their motivation to change? The question also arises as to whether such self-perpetuating "reasoning" and behaviour can, or even could be, effectively challenged and changed by the strategies that have been employed in school anti-bullying programmes to date.

This study, however, based as it is on an acknowledged "short, simple questionnaire", with its emergent nominal data and its simple methods of statistical analysis, can be said to provide only indicative (or, given the comparative novelty of the area of focus [alterophobic bullying]) initial exploratory findings.

It must also be noted that the study was not without its methodological limitations. For example, in constructing the questionnaire, it is apparent on reflection that the definitions used for the five sub-cultures were not "equivalent"; for chavs and emos, some emotional/behavioural aspects were included, but for D4s, moshers/rockers and goths, descriptions were based on purely visual characteristics. The description of chavs included potentially leading phrases such as "rough", "repeatedly engages in anti-social behaviour", and "rowdiness", and emos were described as "emotional, sensitive, shy, and introverted". These descriptions could have exerted an effect on how participants estimated their likely involvement in bullying others and being bullied, respectively, (see Table III and its accompanying text, above). In the further investigation of this area, if a survey method were to be attempted, equivalent definitions would have to be constructed. However, it is also possible to see that alternative research methods (e.g. focus groups, which would allow teenagers own perspectives on sub-cultures 
and the underlying features of alterophobic prejudice to be discerned), would permit for advances in understanding in this area.

\section{Implications for practice}

- The further investigation of alterophobia and alterophobic bullying should prove instructive to researchers and practitioners.

- Since those who are members of "alternative" sub-cultures may be considered "at risk" of bullying, making specific reference to alterophobia in school anti-bullying policies is recommended (as has been the case with homophobic bullying in Ireland).

- An attention to the psychology of prejudice as well as the psychology of aggression should inform research into bullying and the design of anti-bullying interventions in schools.

- The concept of "pro-conformist aggression" may also be of some use in designing anti-bullying interventions in schools.

\section{Note}

1. This fictional character, portrayed in the books, stage plays and national newspaper weekend columns written by the tremendously popular author Paul Howard, would have been familiar to all of the participants in the survey.

\section{References}

Björkqvist, K. and Österman, K. (1999), "Finland”, in Smith, P.K., Morita, Y., Junger-Tas, J., Olweus, D., Catalano, R. and Slee, P. (Eds), The Nature of School Bullying: A Cross National Perspective, Routledge, Abingdon.

Butt, R. (2007), '“Tragedy beyond words' for family as woman, 20, dies after park attack”, The Guardian, 25 August.

Clarke, V., Ellis, S.J., Peel, E. and Riggs, D.W. (2010), Lesbian, Gay, Bisexual, Trans and Queer Psychology: An Introduction, Cambridge University Press, Cambridge.

Cohen, S. (2002), Folk Devils and Moral Panics: The Creation of the Mods and Rockers, 3rd ed., Routledge, Abingdon.

Duncan, N. (1999), Sexual Bullying: Gender Conflict and Pupil Culture in Secondary Schools, Routledge, Abingdon.

Erikson, E.H. (1963), Childhood and Society, 2nd ed., Vintage, London.

Fandrem, H., Ertesvåg, S.K., Strohmeier, D. and Roland, E. (2010), "Bullying and affiliation: a study of peer groups in native and immigrant adolescents in Norway", European Journal of Developmental Psychology, Vol. 7 No. 4, pp. 401-18.

Farrington, D.P. and Ttofi, M.M. (2010), School-based Programs to Reduce Bullying and Victimization, Campbell Systematic Reviews, Oslo.

Hodkinson, P. (2002), Goth: Identity, Style and Subculture, Berg Publishers, Oxford.

Labouvie-Vief, G. (1982), "Dynamic development and mature autonomy: a theoretical prologue", Human Development, Vol. 25, pp. 161-91.

Latané, B. (1981), "The psychology of social impact”, American Psychologist, Vol. 36, pp. 343-56.

Maio, G.R. and Haddock, G. (2009), The Psychology of Attitudes and Attitude Change, Sage, London.

Minton, S.J. (2010), "Students experiences of aggressive behaviour and bully/victim problems in Irish Schools", Irish Educational Studies, Vol. 29 No. 2, pp. 131-52.

Minton, S.J. (2012), Using Psychology in the Classroom, Sage, London.

PAGE 94 | JOURNAL OF AGGRESSION, CONFLICT AND PEACE RESEARCH | VOL. 4 NO. 22012 
Minton, S.J., Dahl, T., O'Moore, A.M. and Tuck, D. (2008), "' ', An exploratory survey of the experiences of homophobic bullying amongst lesbian, gay, bisexual and transgendered young people in Ireland, Irish Educational Studies, Vol. 27 No. 2, pp. 177-91.

Morita, Y., Soeda, H., Soeda, K. and Taki, M. (1999), "Japan”, in Smith, P.K., Morita, Y., Junger-Tas, J., Olweus, D., Catalano, R. and Slee, P. (Eds), The Nature of School Bullying: A Cross National Perspective, Routledge, Abingdon.

Norman, J., Galvin, M. and McNamara, G. (2006), Straight Talk: Researching Gay and Lesbian Issues in the School Curriculum, Gender Equality Unit, Dublin.

O'Higgins-Norman, J., Goldrick, M. and Harrison, K. (2010), Addressing Homophobic Bullying in Second-level Schools, Equality Authority, Dublin.

Olweus, D. (1999), “'Sweden', 'Norway”', in Smith, P.K., Morita, Y., Junger-Tas, J., Olweus, D., Catalano, R. and Slee, P. (Eds), The Nature of School Bullying: A Cross National Perspective, Routledge, Abingdon.

Roland, E. and Auestad, G. (2009), Seksuell orienteering og mobbing (Sexual Orientation and Bullying, University of Stavanger: Centre for Behavioural Research), Senter for atferdsforskning, Universitetet Stavanger, Stavanger.

Roland, E. and Idsøe, T. (2001), "Aggression and bullying", Aggressive Behaviour, Vol. 27 No. 6, pp. 446-61.

Salmivalli, C. and Nieminen, E. (2002), "Proactive and reactive aggression among school bullies, victims, and bully-victims", Aggressive Behaviour, Vol. 28, pp. 30-44.

Salmivalli, C., Lagerspetz, K., Björkqvist, K., Österman, K. and Kaukiainen, A. (1996), "Bullying as a group process: participant roles and their relations to social status within the group", Aggressive Behaviour, Vol. 22, pp. 1-15.

Smith, P.K. (Ed.) (2003), Violence in Schools: The Response in Europe, Routledge-Falmer, London.

Smith, P.K., Pepler, D. and Rigby, K. (2004), Bullying in Schools: How Effective Can Interventions Be? Cambridge University Press, Cambridge.

Smith, P.K., Morita, Y., Junger-Tas, J., Olweus, D., Catalano, R.F. and Slee, P. (Eds) (1999), The Nature of School Bullying: A Cross National Perspective, Routledge, Abingdon.

Tajfel, H. and Turner, J.C. (1986), "An integrative theory of inter-group conflict", in Austin, W.G. and Worchel, S. (Eds), The Social Psychology of Intergroup Relations, 2nd ed., Nelson-Hall, Chicago.

Turner, J.C. and Oakes, P. (1986), "The significance of the social identity concept for social psychology with reference to individualism, interactionism and social influence", British Journal of Social Psychology, Vol. 25 No. 3, pp. 237-52.

Turner, J.C. and Reynolds, K.J. (2010), "The story of social identity", in Postmes, T. and Branscombe, N.R. (Eds), Rediscovering Social Identity, Psychology Press, London.

Wainwright, M. (2008), "Woman dies after drunken gang attacked couple dressed as goths", The Guardian, 13 March.

\section{Corresponding author}

Stephen James Minton can be contacted at: mintonst@tcd.ie

To purchase reprints of this article please e-mail: reprints@emeraldinsight.com Or visit our web site for further details: www.emeraldinsight.com/reprints

VOL. 4 NO. 22012 JOURNAL OF AGGRESSION, CONFLICT AND PEACE RESEARCH | PAGE 95 


\section{This article has been cited by:}

1. Noel Purdy, Conor Mc Guckin. 2014. Disablist bullying in Northern Ireland and the Republic of Ireland: an investigation of student teachers' knowledge, experience and confidence. European Journal of Special Needs Education 1-11. [CrossRef]

2. Stephen James Minton. 2014. Homophobic bullying: evidence-based suggestions for intervention programmes. Journal of Aggression, Conflict and Peace Research 6:3, 164-173. [Abstract] [Full Text] [PDF]

3. Stephen James Minton. 2014. Prejudice and effective anti-bullying intervention: Evidence from the bullying of "minorities". Nordic Psychology 66, 108-120. [CrossRef] 